\title{
The role of usability in the evaluation of accidents: human error or design flaw?
}

\author{
Walter Correia a , Marcelo Soares ${ }^{\text {a }}$, Marina Barros ${ }^{\text {a }}$, Fábio Campos ${ }^{\text {a }}$ \\ ${ }^{a}$ Design Department, CAC, Universidade Federal de Pernambuco, Av. dos Reitores, S/N, Recife-PE, Brazil
}

\begin{abstract}
This article aims to highlight the role of consumer products companies in the heart and the extent of accidents involving these types of products, and as such undesired events take part as an agent in influencing decision making for the purchase of a product that nature on the part of consumers and users. The article demonstrates, by reference, interviews and case studies such as the development of poorly designed products and design errors of design can influence the usage behavior of users, thus leading to accidents, and also negatively affect the next image of a company. The full explanation of these types of questions aims to raise awareness, plan on a reliable usability, users and consumers in general about the safe use of consumer products, and also safeguard their rights before a legal system of consumer protection, even far away by the CDC Code of Consumer Protection.
\end{abstract}

Keywords: usability tests, design, consumer products

\section{Introduction}

Currently, a major trend is apparent for users of new devices, home appliances and consumer products in general, initiate its use through direct operational learning, i.e. trial and error, where most of the time you leave the manual instruction side. The scientific and technological development, alongside the undoubted benefits it brought to people in general, greatly increased the risks for each individual consumer. This is because a single defect in the stage of designing, manufacturing a single error, since the products are manufactured on a large scale can cause damage to thousands of consumers $[6,9]$.

[4] clarifies that any technological advance is to contribute in some way so that there is multiplication of risks arising from defects in industrial products. This opens the way for it to be adopted, with regard to liability for accidents consumption, other types of responsibilities in order to safeguard the rights of injured consumers. The entrepreneurs, designers and planners have a key role with respect to this matter, for they are the main issues involved in legal proceedings that will lead to financial losses and a permanent stain on the image of their products. Although it does not have an apparatus which accounts for the Brazilian population how careless people are with respect to home accidents of nature, and also in relation to household products (consumer products), North American research sources report that only in 1995, approximately 5.5 million people were victims of some type of accident in his own house, and more than 30,500 deaths were recorded, and these numbers are growing according to the same sources. Thus, the worry is that Brazil has to reveal.

[2] affirms that case study is a comprehensive characterization to describe a variety of surveys that collect and record data in a particular case or several cases of individuals to organize an orderly and critical report of an experience, or evaluate it analytically, aiming to make decisions about it or propose a transformation. Thus, for the submission of this article, was performed a case study with a sample taken from the two accidents questionnaires submitted by [3] in a universe of eight accidents.

The selection of the sample who composed the accidents studied was made randomly from contact with some respondents who had registered their email in the questionnaires.

The objectives of this case study were: a) detailed analysis of each accident, b) to analyze the activity through a flowchart of task c) perform a careful analysis of the causes of accidents and d) assess the level of usability of products. The products that were 
part of the study and their accidents were (i) a common drill, leading to a cut and bruise, and (ii) a pressure cooker, causing concussion. The case studies involved the users of accident victims.

They were asked to: a) respond to a previous interview about how the accident happened, b) make a recorded simulation of such accidents; c) answer questions in the SUS - System Usability Scale. The latter aimed to evaluate the degree of usability of each product mentioned, according to [7].

\section{Case study procedure}

During the interview stage with each of the users, the victim of some kind of incident, followed the roadmap proposed by [11], and thus took into account several aspects of the accident such as how this happened, the User's opinion about it, what is the most relevant for the product and the place where the incident happened, where the conditions in which the environment was at the time of the event, and what was the condition of psycho physiological User upon the occurrence of accident.

The accidents simulations were made from the reports sent by users, since it is aimed to reconstruct the situation for future analysis. They were asked to describe the accident, repeatedly, to obtain a recovery as close as possible to the fact. The considerations were based on (i) the "User's voice," which were recorded their descriptions and opinions about the accident, and (ii) the author's own insight to replenish the same. The evaluation of each of the SUS questionnaire was made subjectively, it depends on the User's own opinion, and its quantification and calculations were made based on parameters provided by the SUS.

\subsection{Accident Analysis}

As mentioned previously, accidents collected from questionnaires were recorded and analyzed in detail in accordance with what was reported by users. What is presented in this session comes down to presentation of two of the accidents, an analysis of actions taken by users and, finally, its Fault Tree.

\subsubsection{Accident with a pressure cooker}

For this simulation, from the eight volunteers the one who had suffered an accident with the pressure cooker was selected. In this situation the researcher requested that the artifact to be used in the simulation be similar to the product that was involved in the accident.

The Figures 1 to 6 show a simulation done for the accident with the pressure cooker. It should be pointed out that the actual product involved in the accident was destroyed and, therefore, another of the same brand and model

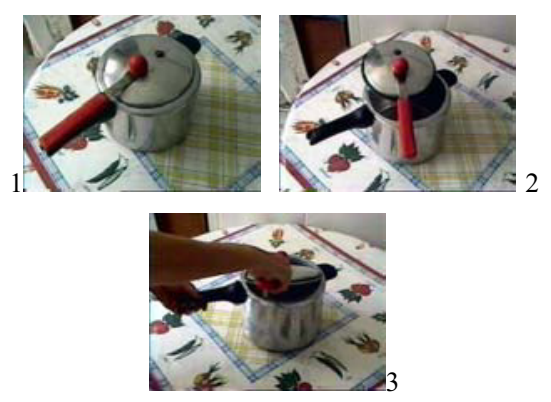

Figures 4, 5 and 6

Simulation of the accident with the pressure cooker
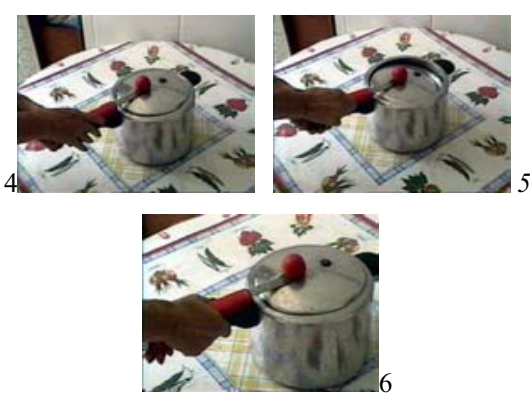

Figures 1,2 and 3

Images of the pressure cooker closed, opened, and in use by user.

The user reported that the pressure cooker exploded shortly after being placed on the stove for cooking beans. She said she did not hear the noise of the exhaust valve. There was no physical damage, because the user was in another room. However, there was damage to the stove, ceiling and the pot.

It should be mentioned that during the simulation, the user took some time (about 30 seconds) impatiently trying to put the cover of the pan in place. The simulation was held without any food inside the pot, and is showed in the Figure 7. 


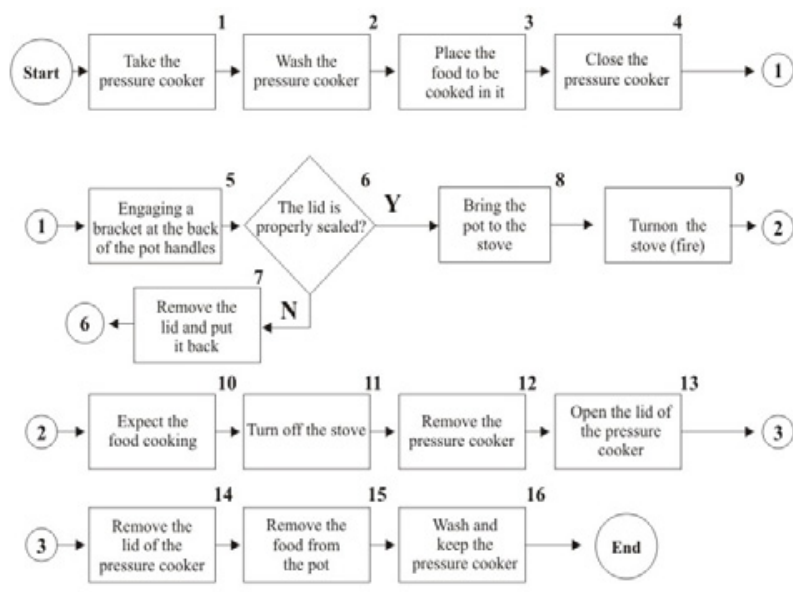

Figure 7

Flowchart of the task to use the pressure cooker

The flowchart of the task was prepared according to the explanation of the user about her procedures for the use of pressure cooker.

The sequence of activities above, described by the user is those that are usually made for the use of an artifact like that which was presented during the simulation.

It was required that during the face to face interview the user demonstrate the following steps in the use of the pressure cooker:

- Place the beans into the pan;

- Secure the top;

- Check to see if the top is secured correctly,

- Take the pan to the stove,

- Turn on the stove,

The user reported that after a few minutes she heard an explosion and the cover of the pot had hit the ceiling.

The user also noted that she knew of other cases in which pressure cookers had exploded while in use. In this study, four users say they had suffered the same type of accidents with the use of pressure cookers. Two of these reported no physical damage to the user, and the other two did not respond to the question.

It was found that the pressure cooker used in the simulation was difficult to seal completely due to the cover of the pot having a side opening between it and the pot. It was necessary to make several attempts at closing the pot to have a secure seal. The Figures 8 and 9 show this defect in the product design.
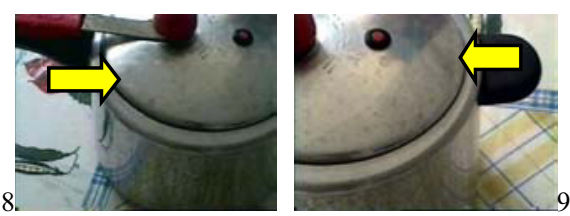

Figures 8 and 9

Images of the pressure cooker - details of the gap in the cover

To reach conclusions about the real cause of the accident, there would be a need for a technical report. However, it can be assumed that failures in the sealing system and / or failures in the exhaust valve may have been the cause of the accident.

The fault tree (Figure 10) was developed based on information gathered from the face-to-face interview. These had been developed taking into account the steps that culminated in the accident.

It is perceived that the lack of reading the instruction manual and inadequate closure of the pressure cooker lid are the main factors for the accident (steps 5 and 6). However, this latter fact is due to some inadequate design of this pressure cooker. Step 4 in the tree demonstrates the insecurity and reluctance of the user regarding the use of the pressure cooker.

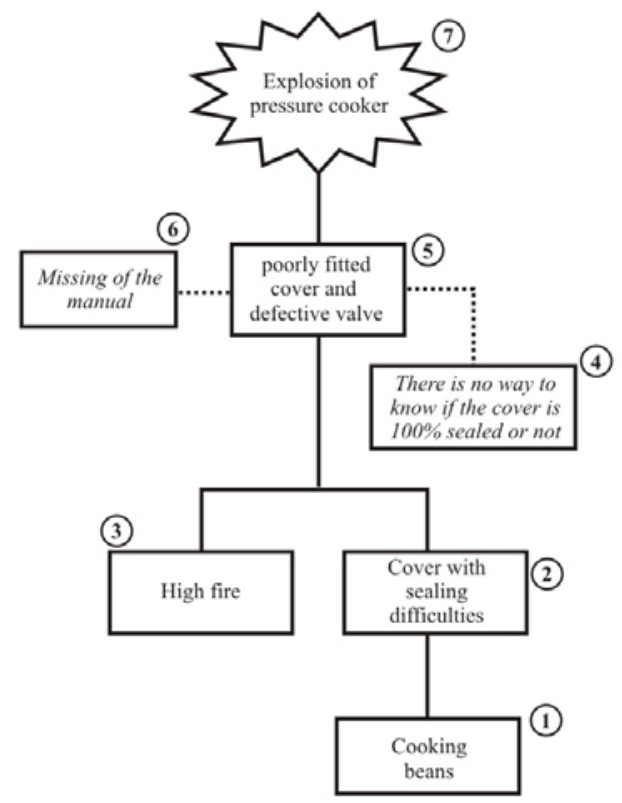

Figure 10

Fault tree for the accident with the pressure cooker 
In this Fault Tree the steps flow from the bottom up. Solid lines represent the direct flow of activity to get to the accident. The dashed lines represent factors involved indirectly with the accident.

However, these faults are to be related since all the accidents could have been avoided if the products had been designed with an emphasis on the caution and safety items, moreover had been paid particular attention to the prevention of misuse of them. It can also be seen that the products analyzed did not show characteristics of a "friendly" product. This fact must consider (i) physical composition (ii) components, (iii) manual of instruction and (iv) warnings.

\subsubsection{Accident with the drill}

The accident occurred when the user tried to make a hole in the wall for placement of a thing using the drill (Figure 11). The photos, shown in Figures 12 and 13, are simulating the use of the drill at the time of the accident. The drill is the same with which the User had his accident.
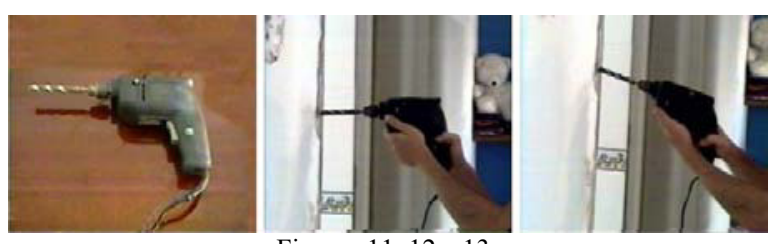

Pictures of the drill and its use for accident's simulation

The related accident happened due to an excessive resistance from the wall, and then the User decided to tilt the drill during operation. At this point, the drill broke and hit the face of the User. There was a bruise and a small cut. Part of the drill remained attached to drill. For a better understanding of the drilling steps activity, was developed a flowchart of the task, as can be seen in figure 14 .

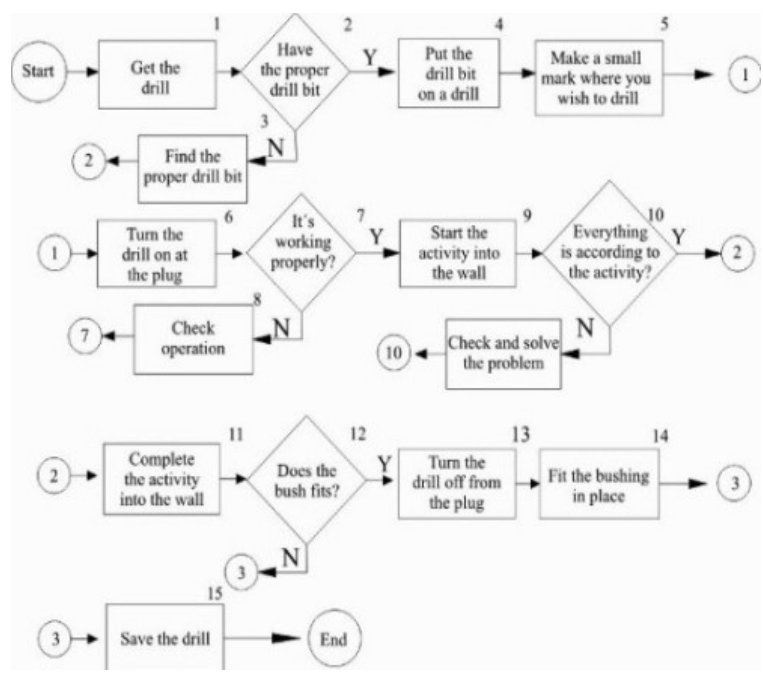

Figure 14

Flowchart of the tasks performed by a drill

The actions that caused the accident were described as follows by user:

- Choice of equipment;

- Search the drill bit ideal for the bush in question;

- Using the reference manual for the drill bit;

- Start the activity using both hands;

- Slightly inclination to try to break the barrier found (strongest part of the wall);

- The drill latch and part of the drill bit goes against the face of the User;

- Cut and bruised in the face of the user.

The manual recommended that the user should always use the drill in a perpendicular position to the action used, in this case is the wall, which should be $90^{\circ}$ with respect to it. The angle adopted by the User may have resulted in the breaking of the drill bit. In the Fault Tree on the drill (Figure 15). These considerations can be checked detailed in accordance with the User-run. 


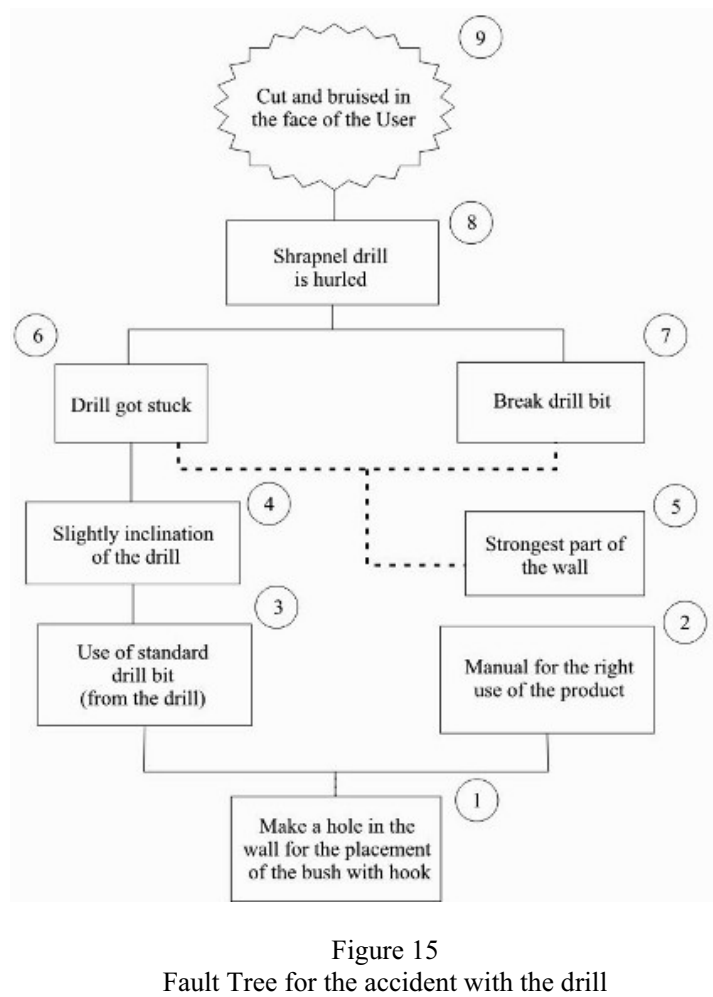

If the User had some more experience with the activity performed (which he affirmed that he didn't), he would know that a wall requires a stronger type of drill bit that, when it is thicker (using an bush to a thicker wall below) the drill bit should be stronger (other material).

\section{Questionnaire with the users: application of SUS - System Usability Scale}

SUS shows to the respondents some few questions to be answered by marking on a satisfaction scale according to the level of agreement or disagreement for each question. After answered and encoded the answers are calculated, through a coefficient given by the SUS, the degree of usability of a given product.

\subsection{Implementation procedures of SUS}

According to the recommendations made by [8] were followed all the procedures for the implementation of SUS, ranging from the explanation on that it was the questionnaire to their weighting and analysis. Through this procedure, it was possible to obtain acceptable results for the study with users. The calculations are presented in the tables 1 and 2 were made based on questionnaires answered by the SUS users followed the order presented by the authors. For a proper understanding of users' responses, it is the " 0 " (zero) as the lowest score for the level of usability and "100" a higher score.

\subsection{SUS analysis for pressure cooker}

As can be seen in Table 1, the pressure cooker had an index of usability of 40 out of 100 . This level of usability means that the product in question leaves much to be desired in how performance and safety. According to the opinion of the user of the product, this product should be taken off the marker.

Table 1

Calculation of the score of usability for the pressure cooker

\begin{tabular}{|l|l|}
\hline $\begin{array}{l}\text { Score of odd-numbered items }= \\
\text { Position in the scale }-1\end{array}$ & $\begin{array}{l}\text { Score of even-numbered items }= \\
5-\text { Position in the scale }\end{array}$ \\
\hline Item $1 \quad 2-1=1$ & Item $2 \quad 5-3=2$ \\
Item $3 \quad 4-1=3$ & Item $45-2=3$ \\
Item $5 \quad 1-1=0$ & Item $6 \quad 5-5=0$ \\
Item $7 \quad-1=3$ & Item $85-5=0$ \\
Item $92-1=1$ & Item $105-2=3$ \\
\hline Sum of odd numbers (NI) & $=8$ \\
\hline Sum of even numbers (NP) & $=8$ \\
\hline Total sum of the items $=$ NI + NP & $=16$ \\
\hline Total score of usability for SUS & $=16 \times 2,5$ \\
Total of items $x 2.5$ & $=40$ \\
\hline
\end{tabular}

\subsection{SUS analysis for drill}

For the second case, the drill, the calculations are presented as follows in table 2 :

Table 2

Calculation for the level of usability of the drill

\begin{tabular}{|l|l|}
\hline $\begin{array}{l}\text { Score of odd number of items }= \\
\text { Rating of }-1\end{array}$ & $\begin{array}{l}\text { Score of even-numbered items = } \\
\text { Rating of }-5\end{array}$ \\
\hline Item $1 \quad 2-1=1$ & Item $2 \quad 5-2=3$ \\
Item $3 \quad 4-1=3$ & Item $4 \quad 5-3=2$ \\
Item $5 \quad 2-1=1$ & Item $6 \quad 5-2=3$ \\
Item $7 \quad 5-1=4$ & Item $8 \quad 5-5=0$ \\
Item $9 \quad 3-1=2$ & Item $105-4=1$ \\
\hline Sum of odd numbers (ON) & $=11$ \\
\hline Sum of even numbers (EN) & $=9$ \\
\hline $\begin{array}{l}\text { Total sum of the items }=\mathrm{NP}+ \\
\text { EN }\end{array}$ & $=20$ \\
\hline $\begin{array}{l}\text { Total score of usability for SUS } \\
\text { Total of items } x 2.5\end{array}$ & $=20 \times 2,5$ \\
& $=50$
\end{tabular}

In the case of the drill, it became a level of usability in the 50 value. Considering the scale from 0 to 100 showed, note that a level of 50 for usability in consumer products can now be considered below the moderate. 
It is evident that the dill in this study, presents a level of usability weak. What, similarly to the previous item, should be considered low to moderate. In general can be seen that the products are presented in a not acceptable scale of usability. This scale should be considered as very low, since the product must meet and satisfy their users (that means 100 points). SUS has through the points where users complained more, try to develop solutions that seek to address gaps in certain product area. As an example, if a User strongly disagree that a product or system is easy to learn to use, you should think about how a more friendly interface can be applied to such product or system, as quoted by [8] and [7].

\section{Conclusions and lessons learned}

It may be noted that that despite the Users' reluctance to remake the incident by claiming difficulty of remembering what happened, or saying that they no longer had the products, the results were satisfactory. The simulations took place at the injured Users' home, bringing him closer to the real in relation to what had happened.

This was asked directly to each user that had any kind of accident. The methodology of [11] was followed step by step, for the most part, for a correct analysis and evaluation of the study. Through the construction of the Fault Tree some lacks were observed, from both the product and the User. It is also clear that, despite the attempt at reconstruction (simulation) of the accident, all were aware that some detail or details might have been forgotten. SUS used in the interviews was the most important to certify that the products analysed in this essay have relatively low level of usability, though one can contest the fact that all the opinions given in here came from the use of products that ended up in an accident.

The authors of the SUS does not define the contents as 40,50 or 60 are low, but show that a scale from 0 to 100 , those two would be the extreme negative and positive end respectively, which can ensure that levels below 70 to 80 , attest, in general, products with low usability, or they could be better studied in their conceptions. It can be affirmed that the accidents analyzed occurred through the fault of the product, and when the lack of the User, attests to the insufficient attention given to some norms of security and usability.
According to [5] and [10], is a mistake of designers and drafters develop a product for themselves thinking that users will act and think like them. Designing for children, the elderly, people with some type of disability or limitation, male or female, tall or short, requires a different degree insight in each case, and this is where is the difference between a good product and a bad product.

It must be clear that not only the aesthetic factor, or meet some of its functions would be sufficient, it is necessary to perform it well and properly, have a formal design and aesthetics in line with the proposal that is intended mainly to the public and to be achieved. The above cases show only a part of a random sample taken from a Brazilian capital. Many cases were found in only a small portion that is not representative. The society estimates that the numbers representing meaningful and are as high as those that were found.

\section{References}

[1] Abbott, H. \& Tyler, M. Safer by Design. A guide to the management and law of designing for product safety. England, Gower, 1997.

[2] Chiozzotti, A. Pesquisa em ciências humanas e sociais. 2 ed. São Paulo, Cortez, 1995.

[3] Correia, W. F. M. Segurança do Produto: Uma Investigação na Usabilidade de Produtos de Consumo. Dissertação de Mestrado, PPGEP / UFPE, 2002.

[4] Denari, Z. Estudo Especial em Responsabilidade Civil por Danos Causados aos Consumidores. Revista de Direito do Consumidor. São Paulo: Editora Revista dos Tribunais, 1994.

[5] Jordan, P.W. An Introduction to Usability. London, Taylor \& Francis, 1998.

[6] Persensky, J. J.; Gagnon, J. L. Evaluation of a hand probe for use in a product regulation. In Proceedings of the Symposium, Human Factors and Industrial Design in Consumer Products. Santa Monica, CA, D. J. Human Factors Society, Consumer products Technical Interest Group. P. 155-172, 1998.

[7] Stanton, N A. \& Barber, C. Error by design: methods for predicting device usability. Design Studies. Vol. 23, $\mathrm{N}^{\circ} 4$. London, Elsevier Science Ltd, July. p. 363 -384, 2002.

[8] Stanton, N A. \& Young, M. S. A Guide to Methodology in Ergonomics. Designing for human use. London, Taylor \& Francis, 1999.

[9] Veiga, A.R. Atitudes de consumidores frente a novas tecnologias. Dissertação de Mestrado, Campinas, SP, Brasil, PUC-Campinas, 1999.

[10] Vendrame, A. C. Acidentes Domésticos - manual de prevenção. São Paulo, LTr Editora. p. 9-13, 2000.

[11] Weegles, M. F. Accidents Involving Consumer Products. Doctorate's Thesys. University of Delft, 1996 